\title{
Indinavir and Nelfinavir inhibit proximal insulin receptor signalling and salicylate abrogates inhibition:potential role of the NFkappa B pathway
}

\author{
Wan Iryani W. ISMAIL ${ }^{\#, \ddagger}$, Judy A. KING ${ }^{\#, \dagger}$, Khawar ANWAR ${ }^{\#}$ and Tahir S. PILLAY**, ${ }^{*, \S 1}$ \\ ${ }^{\#}$ Division of Chemical Pathology, University of Cape Town and $†$ National Health Laboratory Service, Groote \\ Schuur Hospital, Cape Town 7925, South Africa, \$Division of Pharmaceutical Biotechnology, Faculty of Pharmacy, \\ Universiti Teknologi MARA, Puncak Alam Campus, 42300 Bandar Puncak Alam, Selangor, Malaysia, and \\ $\S$ Department of Chemical Pathology, University of Kwazulu-Natal, Durban 4041, South Africa, ${ }^{1}$ Department of \\ Chemical Pathology, University of Pretoria, Pretoria, 0001, South Africa \\ *Correspondence to (present address): Tahir Pillay, Department of Chemical Pathology, University of Pretoria, \\ Pretoria, 0001, South Africa. Email: tspillay@gmail.com
}

Contract grant sponsor:

- National Research Foundation (Rated Researcher Incentive funding) of South Africa,

- the National Health Laboratory Service, South Africa

- Young Lecturer Scheme under Universiti Teknologi MARA

- Ministry of Higher Education of Malaysia.

\begin{abstract}
The molecular basis of insulin resistance induced by HIV protease inhibitors (HPIs) remains unclear. In this study, Chinese hamster ovary cells transfected with high levels of human insulin receptor (CHO-IR) and 3T3-L1 adipocytes were used to elucidate the mechanism of this side effect. Indinavir and nelfinavir induced a significant decrease in tyrosine phosphorylation of the insulin receptor $\beta$-subunit. Indinavir caused a significant increase in the phosphorylation of insulin receptor substrate-1 (IRS-1) on serine 307 (S307) in both CHO-IR cells and 3T3-L1 adipocytes. Nelfinavir also inhibited phosphorylation of Map/ERK kinase without affecting insulin-stimulated Akt phosphorylation. Concomitantly, levels of protein tyrosine phosphatase 1B (PTP1B), suppressor of cytokines signalling-1 and -3 (SOCS-1 and -3), Src homology 2B (SH2B) and adapter protein with a pleckstrin homology domain and an $\mathrm{SH} 2$ domain (APS) were not altered significantly. When CHO-IR cells were pre-treated with sodium salicylate (NaSal), the effects of indinavir on tyrosine phosphorylation of the IR $\beta$-subunit and phosphorylation of IRS-1 at S307 were abrogated. These data suggest a potential role for the NFkB pathway in insulin resistance induced by HPIs.

Keywords:

- HIV protease inhibitors

- insulin resistance

- salicylate

The abbreviations used are: HAART, highly active antiretroviral therapy; HPIs, HIV protease inhibitors; CHO-IR, Chinese hamster ovary cells transfected with high levels of human insulin receptor; IR, insulin receptor; IRS-1, insulin receptor substrate-1; S307, serine 307; PTP1B, protein tyrosine phosphatase 1B; SOCS-1 and -3, suppressor of cytokines signalling-1 and -3; SH2-B, Src homology 2-B; APS, adapter protein with a pleckstrin homology domain and an $\mathrm{SH} 2$ domain; $\mathrm{NF} \kappa \mathrm{B}$, nuclear factor kappa B; IкB, inhibitor kappa B; IKK $\beta$, IкB kinase $\beta$; GLUT4, glucose transporter 4; NaSal, sodium salicylate, Map/Erk Kinase; mitogen-activated/Extracellular signal-regulated protein kinase
\end{abstract}




\section{INTRODUCTION}

After 30 years ago, HIV infection remains a major threat globally in particular in the southern part of sub-Saharan Africa [Dieffenbach and Fauci, 2011]. While HIV vaccine development is a promising solution, the treatment of HIV/AIDS is still of major concern.

The most potent HIV treatment is highly active antiretroviral therapy (HAART). This has increased longevity but has also increased the incidence of various metabolic disorders such as insulin resistance and lipodystrophy, which are associated with type 2 diabetes mellitus and cardiovascular disease respectively [Barbaro, 2002; Florescu and Kotler, 2007; Stein, 2007]. It has emerged that HIV protease inhibitors (HPIs), one of the components of HAART drug therapy, play a critical role in inducing the side effects. These drugs impair insulin-regulated metabolism in adipose tissue [Gougeon et al., 2004].

Previous studies reported that HPI drugs at plasma concentrations $(10 \mu \mathrm{M})$ affect distal steps in the insulin signalling pathway [Murata et al., 2002]. Specifically, the drugs inhibit glucose transporter 4 (GLUT4) at the cell membrane, preventing the uptake of glucose into cells, resulting in hyperglycaemia. However, the precise mechanism whereby the drugs induce insulin resistance and consequent hyperglycaemia is still uncertain [Murata et al., 2002; Noor et al., 2002; Rudich et al., 2005; Rudich et al., 2003].

In this study, we used indinavir, a prototypic HPI, to analyse the effects on the insulin signalling pathway in Chinese hamster ovary cells transfected with high levels of human insulin receptor (CHO-IR) and differentiated murine 3T3-L1 adipocytes. 3T3-L1 adipocytes have a similar morphology and physiology to human adipocytes. The cells also express additional proteins that are not present in CHOIR cells, such as the adapter protein with a pleckstrin homology domain and an SH2 domain (APS), and the glucose transporter GLUT4 [Ahn et al., 2004].

This is the first study in which insulin receptor-transfected cells have been used to investigate the effects of HPIs. We found that indinavir $(50 \mu \mathrm{M})$ inhibited insulin signalling at a proximal level in the insulin signalling cascade. In particular, indinavir inhibited tyrosine phosphorylation of the insulin receptor $\beta$-subunit and its substrate, insulin receptor substrate-1 (IRS-1). This was associated with increased phosphorylation of IRS-1 on serine 307 (S307).

In order to identify the pathway involved, CHO-IR cells were treated with sodium salicylate $(\mathrm{NaSal})(5 \mathrm{mM})$ which inhibits the upstream activator of nuclear factor kappa $\mathrm{B}(\mathrm{NF} \kappa \mathrm{B})$, the I $\mathrm{B}$ kinase $\beta$ (IKK $\beta$ ), resulting in decreased phosphorylation of IRS-1 on S307. Salicylates abrogated the effects of indinavir, implicating the involvement of the NFKB pathway.

\section{MATERIALS AND METHODS}

\section{Materials}

CHO-IR cells and 3T3-L1 pre-adipocytes were used as previously described [Ahmed and Pillay, 2003]. Media and other tissue culture supplies were purchased from Sigma-Aldrich Co. and Lonza Group Ltd. Indinavir was donated by Merck \& Co. and NaSal was obtained from Sigma-Aldrich Co.Nelfinavir was obtained from the NIH Aids reagents program. The antibodies used in the study were: mouse monoclonal anti-phosphotyrosine (PY20) (BD Transduction), rabbit polyclonal: anti-insulin receptor $\beta$-subunit, antiprotein tyrosine phosphatase 1B (PTP1B), anti-suppressor of cytokines signalling-1 (SOCS-1) and antiSOCS-3, goat polyclonal anti-actin, mouse anti-goat horseradish peroxidase (HRP)-conjugated secondary antibody and goat anti-rabbit HRP-conjugated secondary antibody (Santa Cruz Biotechnology, Inc.), rabbit polyclonal: anti-IRS-1, anti-phosphoIRS-1 at S307 and anti-APS (Cell Signaling Technology, Inc.), goat anti-mouse HRP-conjugated secondary antibody (Thermo Fisher Scientific, Inc.), and rabbit polyclonal anti-Src homology 2-B (SH2B) (produced in the authors' laboratory) [Kotani et al., 1998]. 


\section{Cell culture}

CHO-IR cells were cultured in Ham's F12 mixture culture medium and incubated at $37^{\circ} \mathrm{C}$ in a $5 \% \mathrm{CO}_{2}$ incubator. 3T3-L1 pre-adipocytes were cultured and differentiated as previously described [Ahn et al., 2004].

\section{Sample preparation}

CHO-IR cells $\left(1 \times 10^{5}\right.$ cells $\left./ \mathrm{ml}\right)$ were cultured in 6-well plates. 3T3-L1 adipocytes were differentiated and grown to full confluence in $3.5 \mathrm{~cm}$ dishes [Mehra et al., 2007] and serum-starved for $16 \mathrm{~h}$. Prior to aspirating the serum-free medium (SFM) from the cells, the cells were stimulated with insulin (10 ng/ml) for $5 \mathrm{~min}$. The cells were lysed in lysis buffer [50 mM HEPES, pH 7.5, 1\% NP40, 10\% glycerol, $50 \mathrm{mM}$ $\mathrm{NaCl}$, protease inhibitor and phosphatase inhibitor (Roche)] and mixed with $5 \mathrm{x}$ Laemmli buffer ( $25 \mathrm{mM}$ Tris, $\mathrm{pH} 6.8,2 \%$ SDS, $0.002 \%$ bromophenol blue, $10 \%$ glycerol and 5\% 2-mercaptoethanol) prior to boiling at $100^{\circ} \mathrm{C}$ for $5 \mathrm{~min}$. The experiment was repeated using cells pre-treated with $\mathrm{NaSal}(5 \mathrm{mM})$ for 1 $\mathrm{h}$ prior to indinavir $(100 \mu \mathrm{M})$ treatment for $16 \mathrm{~h}$ in SFM. NaSal, indinavir and nelfinavir were prepared as previously described [Vernochet et al., 2005; Yuan et al., 2001]. The impact of the solvent and cell viability were monitored in preliminary experiments. The concentrations used did not affect cell viability.

\section{Immunoblot/Western blot analysis}

Immunoblotting was performed as previously described [Ahmed and Pillay, 2003]. Phosphorylation of IR $\beta$-subunit and IRS-1 were detected using anti-PY20 antibody. The proteins were visualised using chemiluminescent reagent (Pierce) and quantified by ChemiImager software (Fluorchem). The membrane was stripped with a stripping buffer $(62.5 \mathrm{mM}$ Tris, $\mathrm{pH}$ 6.8, 2\% SDS and $100 \mathrm{mM}$ of 2-mercaptoethanol) at $50^{\circ} \mathrm{C}$ for $15 \mathrm{~min}$ to reprobe with the other antibodies listed in the materials section. Anti-actin was used as a loading control for cellular protein. The section of the membrane containing the protein was cut into a horizontal strip and used for probing and reprobing. Membranes were probed and stripped up to two times in total only.

\section{Statistical analysis}

Data are expressed as the mean \pm S.E.M of at least triplicate experiments. Statistical comparisons were made using Student's $t$-test and factorial-ANOVA.

\section{Results}

Effect of HPIs on the phosphorylation of insulin receptor $\beta$-subunit and IRS-1

CHO-IR cells and 3T3-L1 adipocytes were pre-treated with indinavir for $16 \mathrm{~h}$ prior to stimulation with a submaximal insulin concentration $(10 \mathrm{ng} / \mathrm{ml})(1.7 \mathrm{nM})$ for $5 \mathrm{~min}$ [Figures 1 and 2]. In CHO-IR cells, samples pre-treated with indinavir and stimulated with insulin showed a significant decrease in tyrosine phosphorylation of the insulin receptor $\beta$-subunit $(p=0.02)$ [Figure 1(a)] and in the phosphorylation of IRS-1 $(p=0.0002)$ [Figure 1(b)]. In 3T3-L1 adipocytes under the same conditions, there was a significant decrease in tyrosine phosphorylation of the insulin receptor $\beta$-subunit $(\mathrm{p}=0.003)$ [Figure 2(a)] and IRS-1 $(\mathrm{p}=$ 0.0002) [Figure 2(b)], as compared with cells stimulated with insulin only.

The expression levels of total insulin receptor $\beta$-subunit and IRS- 1 were also examined to determine if the decreased tyrosine phosphorylation was due to changes in protein expression. There were no significant differences in expression levels of insulin receptor $\beta$-subunit and IRS- 
1 among the samples, indicating that the decreased signal observed [Figures 1 and 2] was due to a decrease in tyrosine phosphorylation rather than in total protein levels. In addition, the expression level of actin was also examined as a loading control for cellular protein. The change in IRS-1 phosphorylation in figure $1 \mathrm{~b}$ was not significant when normalized to protein levels.

Based on these results, two possible hypotheses could be invoked: viz. 1) the drug inhibits the insulin receptor kinase directly or 2) the drug effects are indirect, and involve a regulator of tyrosine phosphorylation.

In order to test these hypotheses, the blots were stripped and reprobed with antibodies against phosphotyrosine regulatory proteins of insulin signalling, such as phosphoIRS-1 at S307, PTP1B, SOCS-1 and -3, SH2-B and APS.

We performed additional experiments with nelfinavir, a newer protease inhibitor (fig 1c, d) Similarly to indinavir, nelfinavir also inhibited insulin-stimulated tyrosine phosphorylation of the receptor b-subunit and IRS proteins by greater than 50\%. Interestingly, nelfinavir also inhibited insulin-stimulated Map Kinase activation by more than 50\% whilst leaving Akt activation largely intact.

\section{Effect of HPIs on regulatory proteins in the insulin signalling pathway}

There was a significant increase in the level of phosphorylated S307 on IRS-1 in both cell lines, CHO-IR cells $(p=0.001)$ [Figure 3(a)] and 3T3-L1 adipocytes $(p=0.004)$ [Figure 4(a)], treated with indinavir and then stimulated with insulin, compared to cells stimulated with insulin alone. These results were not accompanied by a change in the level of total IRS-1 [Figures 3(a) and 4(a)].

The expression levels of PTP1B, SOCS-1 and -3, and SH2B in CHO-IR cells after pretreatment with indinavir were not significantly different [Figure 3(b,c,d,e)]. In 3T3-L1 adipocytes, pre-treatment with indinavir did not significantly alter the expression levels of PTP1B, SOCS-1 and -3, SH2B and APS [Figure 4(b,c,d,e,f)].

\section{Effects of indinavir after NaSal pre- treatment}

CHO-IR cells were used to examine the effect of NaSal on indinavir treatment, as the cells have a high level of insulin receptor expression, which facilitates more sensitive detection of changes in signalling proteins than in 3T3-L1 adipocytes.

Cells pre-treated with $\mathrm{NaSal}$ prior to treatment with indinavir showed a significant increase in insulin-stimulated tyrosine phosphorylation of the insulin receptor $\beta$-subunit $(p=0.002)$ [Figure 5(a)] when compared to cells treated with indinavir and insulin only. In fact, insulin-stimulated tyrosine phosphorylation was restored to the levels seen in the presence of insulin only, without indinavir. This indicates that NaSal blocked the effects of indinavir to inhibit tyrosine phosphorylation of the insulin receptor $\beta$-subunit.

A slight, but statistically insignificant, increase in insulin-stimulated tyrosine phosphorylation of IRS-1 was also observed after NaSal treatment, when compared to cells treated with indinavir and insulin alone [Figure 5(b)].

NaSal also decreased phosphorylation of IRS-1 at S307 twofold, although this was not statistically significant compared to cells treated with indinavir followed by insulin [Figure 5(c)]. These results suggest that NaSal treatment abrogated the effects of indinavir to inhibit tyrosine 
phosphorylation of the insulin receptor $\beta$-subunit and IRS-1 in parallel with a decrease in phosphorylation of IRS-1 at S307 [Figure 5(a,c)].

\section{Discussion}

The effects of HPIs have been examined in numerous studies [Wan Iryani et al., 2009]. The majority of studies have largely focussed on downstream events in the insulin signalling pathway. HPIs, including indinavir, were found to inhibit glucose uptake by inhibiting GLUT4 at the cell surface [Murata et al., 2002; Noor et al., 2002] without any effect on insulin receptor phosphorylation using insulin concentrations of $1 \mu \mathrm{M}$. There was no evidence of any upstream effect using this supraphysiological concentration of insulin. There is a paucity of studies that have examined proximal steps in the insulin signalling cascade, including insulin binding to the receptor and activation of the intrinsic tyrosine kinase activity and subsequent tyrosine phosphorylation of substrate, where direct or indirect drug-induced inhibition may occur.

In this study, for the first time, CHO-IR cells were used to analyse the effects of HPIs on the insulin receptor $\beta$-subunit phosphorylation and tyrosine kinase activation. The results reveal that indinavir $(50 \mu \mathrm{M})$ treatment for $16 \mathrm{~h}$ inhibited tyrosine phosphorylation of insulin receptor $\beta$-subunit and IRS-1 in the insulin signalling pathway. These are early events following insulin binding to the insulin receptor. The same effect was also observed in 3T3-L1 adipocytes. In a prior investigation using HepG2 hepatoma cells, it was reported that indinavir $(100 \mu \mathrm{M})$ treatment for $48 \mathrm{~h}$ decreased tyrosine phosphorylation of the IRS-1 protein but not phosphorylation of the insulin receptor itself [Schutt et al., 2000]. The effects of indinavir may be different in different cell lines depending on the experimental model and duration of exposure [Ben-Romano et al., 2003; Kovsan et al., 2009; Noor et al., 2006]. However, it would be technically difficult to analyse insulin receptor beta subunit phosphorylation in 3T3-L1 adipocytes at physiological insulin concentrations because of the level of expression, hence the rationale for using CHO-IR cells in this study. The indinavir concentration used in this study was higher than reported plasma concentrations $(11 \mu \mathrm{M})$ [Lin, 1999]. A previous study reported that indinavir accumulated in adipose tissue [Vernochet et al., 2005]. Therefore, in vivo drug concentration at plasma levels do not reflect the actual drug concentration at tissue levels which may be higher than the circulating levels [Ranganathan and Kern, 2002]. The effects of indinavir observed in present study are unlikely to be due to cellular toxicity because in a previously reported study, indinavir was not toxic to cells even at concentrations of $100 \mu \mathrm{M}$ [Germinario and Colby-Germinario, 2003]. Therefore, the range of indinavir used in the observation was in the range $(0-100 \mu \mathrm{M})$. We did not observe any toxic effects on either CHO cells or adipocytes at these concentrations.

In a cellular context ex vivo, the effects of indinavir may only be apparent at submaximal insulin concentrations, which are more typical of physiological circulating insulin concentrations. For this reason, we have used a submaximal concentration of $10 \mathrm{ng} / \mathrm{ml}(1.7 \mathrm{nM})$ insulin to stimulate cells even though the maximal activation of the insulin receptor tyrosine phosphorylation is observed at levels approximately at least 10 -fold higher than $10 \mathrm{ng} / \mathrm{ml}$ i.e. 100 $\mathrm{ng} / \mathrm{ml}(17 \mathrm{nM})$. In other words, even though the maximal activation of insulin receptor tyrosine phosphorylation is observed at much higher levels of insulin in CHO-IR cells, the pharmacological effects of insulin being used at maximal concentrations in a cell line that overexpresses insulin receptors at such a high level may mask the inhibitory effects of indinavir. This difference is important when comparing our results with those of Murata et al (2002). In 
this paper the authors have used a maximal and supraphysiological concentration of insulin (1 $\mu \mathrm{M})$ to stimulate the cells. In all of our studies, we used $10 \mathrm{ng} / \mathrm{ml}(1.7 \mathrm{nM})$, which is a 1000 -fold less and more similar to a physiological concentration. We have also found that when we used $100 \mathrm{ng} / \mathrm{ml}(17 \mathrm{nM})$, we did not observe any effects on the insulin receptor kinase (data not shown)

The inhibition of tyrosine phosphorylation of the insulin receptor kinase and its substrate, IRS-1, implies that indinavir and nelfinavir interact at a very proximal step in the insulin signalling pathway. Interestingly, nelfinavir showed a significant on Map kinase phosphorylation, whilst leaving Akt phosphorylation largely intact. There are two possible mechanisms to explain this. The drug may act directly to inhibit the insulin receptor kinase or the drug may affect other proteins that regulate the intrinsic tyrosine kinase activity. In order to address this hypothesis, the blots were stripped and reprobed with antibodies against regulatory proteins of insulin receptor signalling such as Serine 307 phosphorylated IRS-1 (phosphoIRS-1 at S307), PTP1B, SOCS-1 and -3, SH2B and APS.

The protein expression of PTP1B in both cell lines before and after pre-treatment with indinavir was not significantly different. PTP1B, a tyrosine phosphatase, may negatively regulate insulin signalling by binding to the tyrosine phosphorylated proteins, insulin receptor $\beta$-subunit and IRS-1 [Cheng et al., 2002] and catalysing dephosphorylation. However, a previous study suggested that total PTPase activity, but not the activity of PTP1B, is associated with the inhibition of insulin-stimulated glucose transport in adipose tissue [Wu et al., 2003].

The protein expression of SOCS-1 and -3 in CHO-IR cells, and SOCS-3 in 3T3-L1 adipocytes was not significantly different before and after treatment with indinavir. However, the protein expression of SOCS-1 in 3T3-L1 adipocytes before insulin stimulation, was significantly increased as a result of the indinavir treatment. This suggests that increased expression of SOCS1 could potentially play a regulatory role in 3T3-L1 adipocytes.

SOCS-1 and -3 are adapter proteins that can bind to the insulin receptor $\beta$-subunit or IRS1 or IRS-2 to inhibit downstream signalling. Increased SOCS-1 and -3 expression have been reported to induce insulin resistance by preventing tyrosine phosphorylation and subsequent activation of IRS-1 and -2 proteins [Carper et al., 2008]. In addition, SOCS-1 and -3 have been reported to negatively regulate the insulin signalling pathway, without modifying the insulin receptor tyrosine kinase activity [Emanuelli et al., 2001].

Moreover, SOCS-1 and -3 expression can be induced by TNF- $\alpha$ [Emanuelli et al., 2001]. However, this cytokine is released from immune cells and adipose tissue and not from CHO-IR cells. Thus, there was no change in SOCS-1 and -3 protein expression in CHO-IR cells following treatment with indinavir. Similarly, the protein expression of SOCS-3 was also not significantly altered in 3T3-L1 adipocytes treated with the drug. However, there was an alteration in SOCS-1. Therefore, the current investigation indicated that in CHO-IR cells, these proteins are not involved in decreasing phosphorylation of insulin receptor $\beta$-subunit. However, SOCS-1 may play a role in 3T3-L1 adipocytes.

$\mathrm{SH} 2 \mathrm{~B}$ (aka SH2B1) is an adapter protein involved in the signalling pathway mediated by insulin tyrosine kinases and Janus kinase. Deletion of the adapter protein gene in mice results in severe obesity, infertility, and leptin and insulin resistance [Maures et al., 2007]. This protein has also been shown to regulate the tyrosine phosphorylation state of the insulin receptor [Ahmed and Pillay, 2001]. However, the expression of SH2B in CHO-IR cells and 3T3-L1 adipocytes was not significantly altered after treatment with indinavir. 
APS (aka SH2B2) and SH2B have similar roles, and these proteins may delay dephosphorylation of the insulin receptor kinase and IRS-1 and -2 in the insulin signalling pathway [Ahmed and Pillay, 2001; Ahmed and Pillay, 2003]. The adapter protein, APS, however, binds the insulin receptor with a higher affinity than SH2B [Ahmed and Pillay, 2001; Ahmed and Pillay, 2003]. CHO-IR cells lack endogenous APS protein [Ahmed et al., 2000]. Therefore, only this protein was able to analyse in 3T3-L1 adipocytes [Ahn et al., 2004]. The protein expression of APS in 3T3-L1 adipocytes treated with indinavir was not significantly different before and after treatment with indinavir.

Indinavir treatment resulted in a significant increase in phosphorylation of IRS-1 at S307 in both CHO-IR cells and 3T3-L1 adipocytes. Serine phosphorylation of IRS-1 is known to inhibit phosphorylation of the insulin receptor. Indinavir may induce pro-inflammatory cytokines such as TNF- $\alpha$ or unknown cytokines in the cells, which activate IKK $\beta$. IKK $\beta$ is a serine kinase that regulates the activation of $\mathrm{NF} \kappa \mathrm{B}$, a critical activator of genes involved in inflammation and immunity. Prior to activation, $N F \kappa B$ is bound to the inhibitor $\kappa \mathrm{B}(\mathrm{I} \kappa \mathrm{B})$. The activated IKK $\beta$

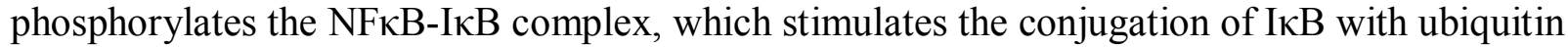
and the subsequent degradation of $\mathrm{I} \kappa \mathrm{B}$ protein in the proteasome, leading to the nuclear translocation of NFאB [Tergaonkar, 2006].

Activation of IKK $\beta$ also induces serine phosphorylation of IRS-1, as IRS-1 is a substrate of IKK $\beta$. This phosphorylation blocks interactions with the insulin receptor $\beta$-subunit, decreases tyrosine phosphorylation, and inhibits insulin action in the cells [Aguirre et al., 2002; Gao et al., 2003].

High doses of salicylate (4 to $10 \mathrm{~g}$ per day), including NaSal and aspirin, are known to reduce blood glucose concentrations in diabetic patients via inhibition of NFאB and its upstream activator IKK $\beta$ [Yuan et al., 2001]. In the present study, NaSal was used for the first time in the context of cells treated with HPIs. In CHO-IR cells treated with HPIs, our findings reveal that the drug inhibits the effects of indinavir on insulin receptor tyrosine phosphorylation even at 100 $\mu \mathrm{M} .100 \mu \mathrm{M}$ of indinavir was used to obtain the maximal effect of the drug on insulin receptor tyrosine phosphorylation. A significant increase of tyrosine phosphorylation of insulin receptor $\beta$-subunit in cells pre-treated with NaSal prior to treatment with HPI drug was observed and this is consistent with the known effects of NaSal on the activation of IKK $\beta$. NaSal also increased tyrosine phosphorylation of IRS-1 slightly and decreased serine phosphorylation of IRS-1 by 2fold. This was associated with a decreased inhibition of tyrosine phosphorylation in response to indinavir i.e. a blockade of the effects of indinavir. Based on these results, we can hypothesize that HPIs may induce insulin resistance via the NFkB pathway.

In conclusion, PTP1B, SOCS-1 and $-3, \mathrm{SH} 2 \mathrm{~B} 1$ and APS, the insulin signalling regulatory proteins, were not altered after indinavir treatment indicating that changes in the expression of these proteins are unlikely to play a role in the insulin resistance induced by antiretroviral protease inhibitors.However, a lack of expression does not exclude a role. However, we show for the first time that NaSal, possibly acting by blocking IKK $\beta$, abrogates the effect of indinavir on tyrosine phosphorylation of the insulin receptor $\beta$-subunit by decreasing phosphoIRS-1 S307. We conclude, therefore, that HIV protease inhibitors inhibit insulin receptor tyrosine phosphorylation indirectly via the NFאB pathway as a secondary effect involving a regulator of tyrosine phosphorylation, viz. the level of phosphorylation of IRS-1 at S307. Salicylates may therefore provide a novel therapy for HIV protease inhibitor-induced insulin resistance and lipodystrophy. These effects of anti-retroviral drugs are but one example of the complex effects 
that protease inhibitors may have, including effects on the endoplasmic reticulum and oxidative stress and the alteration of adipokines (Hruz, 2011).

\section{ACKNOWLEDGEMENTS}

This work was funded by the National Research Foundation (Rated Researcher Incentive funding) of South Africa, the National Health Laboratory Service, South Africa and the Young Lecturer Scheme under Universiti Teknologi MARA and Ministry of Higher Education of Malaysia.

We would like to give our thanks to Prof. J. F. F. Weber for his review.

The authors have no conflicts of interest to declare.

\section{References}

Aguirre V, Werner ED, Giraud J, Lee YH, Shoelson SE, White MF. 2002. Phosphorylation of Ser307 in insulin receptor substrate-1 blocks interactions with the insulin receptor and inhibits insulin action. J Biol Chem 277:1531-7.

Ahmed Z, Pillay TS. 2001. Functional effects of APS and SH2-B on insulin receptor signalling. Biochem Soc Trans 29:529-34.

Ahmed Z, Pillay TS. 2003. Adapter protein with a pleckstrin homology (PH) and an Src homology 2 (SH2) domain (APS) and SH2-B enhance insulin-receptor autophosphorylation, extracellular-signal-regulated kinase and phosphoinositide 3-kinase-dependent signalling. Biochem J 371:405-12.

Ahmed Z, Smith BJ, Pillay TS. 2000. The APS adapter protein couples the insulin receptor to the phosphorylation of c-Cbl and facilitates ligand-stimulated ubiquitination of the insulin receptor. FEBS Lett 475:31-4.

Ahn MY, Katsanakis KD, Bheda F, Pillay TS. 2004. Primary and essential role of the adaptor protein APS for recruitment of both c-Cbl and its associated protein CAP in insulin signaling. J Biol Chem 279:21526-32.

Barbaro G. 2002. HIV infection, antiretroviral therapy and cardiovascular risk. J Cardiovasc Risk 9:295-300.

Ben-Romano R, Rudich A, Torok D, Vanounou S, Riesenberg K, Schlaeffer F, Klip A, Bashan N. 2003. Agent and cell-type specificity in the induction of insulin resistance by HIV protease inhibitors. AIDS 17:23-32.

Carper MJ, Cade WT, Cam M, Zhang S, Shalev A, Yarasheski KE, Ramanadham S. 2008. HIVprotease inhibitors induce expression of suppressor of cytokine signaling-1 in insulinsensitive tissues and promote insulin resistance and type 2 diabetes mellitus. Am J Physiol Endocrinol Metab 294:E558-67.

Cheng A, Dube N, Gu F, Tremblay ML. 2002. Coordinated action of protein tyrosine phosphatases in insulin signal transduction. Eur J Biochem 269:1050-9.

Dieffenbach CW, Fauci AS. 2011. Thirty Years of HIV and AIDS: Future Challenges and Opportunities. Ann Intern Med 154:766-71.

Emanuelli B, Peraldi P, Filloux C, Chavey C, Freidinger K, Hilton DJ, Hotamisligil GS, Van Obberghen E. 2001. SOCS-3 inhibits insulin signaling and is up-regulated in response to tumor necrosis factor-alpha in the adipose tissue of obese mice. J Biol Chem 276:47944-9.

Florescu D, Kotler DP. 2007. Insulin resistance, glucose intolerance and diabetes mellitus in HIV-infected patients. Antivir Ther 12:149-62. 
Gao Z, Zuberi A, Quon MJ, Dong Z, Ye J. 2003. Aspirin inhibits serine phosphorylation of insulin receptor substrate 1 in tumor necrosis factor-treated cells through targeting multiple serine kinases. J Biol Chem 278:24944-50.

Germinario RJ, Colby-Germinario SP. 2003. The effect of human immunodeficiency virus-1 protease inhibitors on the toxicity of a variety of cells. In Vitro Cell Dev Biol Anim 39:275-9.

Gougeon ML, Penicaud L, Fromenty B, Leclercq P, Viard JP, Capeau J. 2004. Adipocytes targets and actors in the pathogenesis of HIV-associated lipodystrophy and metabolic alterations. Antivir Ther 9:161-77.

Hruz P. 2011 Molecular mechanisms for insulin resistance in treated HIV-infection. Best Pract Res Clin Endocrinol Metab 25(3): 459-68

Kotani K, Wilden P, Pillay TS. 1998. SH2-Balpha is an insulin-receptor adapter protein and substrate that interacts with the activation loop of the insulin-receptor kinase. Biochem J 335 ( Pt 1):103-9.

Kovsan J, Osnis A, Maissel A, Mazor L, Tarnovscki T, Hollander L, Ovadia S, Meier B, Klein J, Bashan N, Rudich A. 2009. Depot-specific adipocyte cell lines reveal differential druginduced responses of white adipocytes--relevance for partial lipodystrophy. Am J Physiol Endocrinol Metab 296:E315-22.

Lin JH. 1999. Role of pharmacokinetics in the discovery and development of indinavir. Adv Drug Deliv Rev 39:33-49.

Maures TJ, Kurzer JH, Carter-Su C. 2007. SH2B1 (SH2-B) and JAK2: a multifunctional adaptor protein and kinase made for each other. Trends Endocrinol Metab 18:38-45.

Mehra A, Macdonald I, Pillay TS. 2007. Variability in 3T3-L1 adipocyte differentiation depending on cell culture dish. Anal Biochem 362:281-3.

Murata H, Hruz PW, Mueckler M. 2002. Indinavir inhibits the glucose transporter isoform Glut4 at physiologic concentrations. AIDS 16:859-63.

Noor MA, Flint OP, Maa JF, Parker RA. 2006. Effects of atazanavir/ritonavir and lopinavir/ritonavir on glucose uptake and insulin sensitivity: demonstrable differences in vitro and clinically. AIDS 20:1813-21.

Noor MA, Seneviratne T, Aweeka FT, Lo JC, Schwarz JM, Mulligan K, Schambelan M, Grunfeld C. 2002. Indinavir acutely inhibits insulin-stimulated glucose disposal in humans: a randomized, placebo-controlled study. AIDS 16:F1-8.

Ranganathan S, Kern PA. 2002. The HIV protease inhibitor saquinavir impairs lipid metabolism and glucose transport in cultured adipocytes. J Endocrinol 172:155-62.

Rudich A, Ben-Romano R, Etzion S, Bashan N. 2005. Cellular mechanisms of insulin resistance, lipodystrophy and atherosclerosis induced by HIV protease inhibitors. Acta Physiol Scand 183:75-88.

Rudich A, Konrad D, Torok D, Ben-Romano R, Huang C, Niu W, Garg RR, Wijesekara N, Germinario RJ, Bilan PJ, Klip A. 2003. Indinavir uncovers different contributions of GLUT4 and GLUT1 towards glucose uptake in muscle and fat cells and tissues. Diabetologia 46:64958.

Schutt M, Meier M, Meyer M, Klein J, Aries SP, Klein HH. 2000. The HIV-1 protease inhibitor indinavir impairs insulin signalling in HepG2 hepatoma cells. Diabetologia 43:1145-8.

Stein JH. 2007. Cardiovascular risks of antiretroviral therapy. N Engl J Med 356:1773-5.

Tergaonkar V. 2006. NFkappaB pathway: a good signaling paradigm and therapeutic target. Int $\mathbf{J}$ Biochem Cell Biol 38:1647-53. 
Vernochet C, Azoulay S, Duval D, Guedj R, Cottrez F, Vidal H, Ailhaud G, Dani C. 2005. Human immunodeficiency virus protease inhibitors accumulate into cultured human adipocytes and alter expression of adipocytokines. J Biol Chem 280:2238-43.

Wan Iryani WI, King JA, Pillay TS. 2009. Insulin resistance induced by antiretroviral drugs: Current understanding of molecular mechanisms JEMDSA 14:129-132.

Wu X, Hardy VE, Joseph JI, Jabbour S, Mahadev K, Zhu L, Goldstein BJ. 2003. Protein-tyrosine phosphatase activity in human adipocytes is strongly correlated with insulin-stimulated glucose uptake and is a target of insulin-induced oxidative inhibition. Metabolism 52:705-12.

Yuan M, Konstantopoulos N, Lee J, Hansen L, Li ZW, Karin M, Shoelson SE. 2001. Reversal of obesity- and diet-induced insulin resistance with salicylates or targeted disruption of Ikkbeta. Science 293:1673-7.

\section{Figure legends}

The abbreviations used in the figures are:

NaSal; sodium salicylate

pIRS-1 (PY20) ; tyrosine phosphorylation of IRS-1 and tIRS-1 = total IRS-1.

pIR (PY20) ;tyrosine phosphorylation of IR

pS307; phosphorylated serine at residue 307

PTP1B; protein tyrosine phosphatase $1 \mathrm{~B}$,

SH2B ; Src homology 2 B

SOCS-1; suppressor of cytokines signalling 1,

SOCS-3 ;suppressor of cytokines signalling 3,

tIR $\beta$; total insulin receptor $\beta$-subunit

Fig. 1. Inhibition of insulin-stimulated tyrosine phosphorylation by indinavir and nelfinavir in CHO-IR cells. a) CHO-IR cells were treated with indinavir $(50 \mu \mathrm{M})$ for $16 \mathrm{~h}$ followed by insulin stimulation. The cells were then lysed and the lysates subjected to immunoblotting with antiphosphotyrosine PY20 antibody (upper panels). The blots were then stripped and reprobed with anti-IR $\beta$ subunit (1a), anti-IRS-1(1b) and anti-actin (lower panels). Bound antibodies were visualised by chemiluminescence. Chemiluminescence was quantified by realtime imaging. The band intensity of the proteins from five independent experiments was normalized to the band intensity of total IR or IRS protein. Data are shown as the mean \pm S.E.M. $(n=5)$. pIR $(P Y 20)=$ tyrosine phosphorylation of $\operatorname{IR}, \operatorname{tIR} \beta=$ total insulin receptor $\beta$-subunit, pIRS-1 (PY20) = tyrosine phosphorylation of IRS-1 and tIRS- $1=$ total IRS-1. c) Cells were treated with nelfinavir as indicated and analysed by anti-phosphotyrosine immunoblotting and blotting for phosphor-Mapkinase and phosphoAkt and total Mapkinase and Akt. The quantification of the chemiluminescence is illustrated in the graphs from 3 independent experiments. $* * \mathrm{p}<0.05$, using student $t$-test.

Fig. 2. Inhibition of insulin-stimulated tyrosine phosphorylation by indinavir in 3T3-L1 adipocytes. 3T3-L1 adipocytes were treated with varying concentrations of indinavir for $16 \mathrm{~h}$ before and after insulin stimulation. The cells were then lysed and the lysates subjected to immunoblotting with antiphosphotyrosine PY20 antibody (upper panels). The blots were then stripped and reprobed with anti-IR $\beta$ subunit (2a), anti-IRS-1(2b) and anti-actin (lower panels). Bound antibodies were visualised by chemiluminescence. Chemiluminescence was quantified by realtime imaging. The band intensity of the proteins from six independent experiments was normalized to the band intensity of total IR or IRS protein. Data are shown as the mean \pm S.E.M. $(n=6)$. pIR PY20 $=$ tyrosine phosphorylation of IR, $\operatorname{tIR} \beta=$ 
total insulin receptor $\beta$-subunit, pIRS-1 (PY20) = tyrosine phosphorylation of IRS-1 and tIRS-1 = total IRS-1, ${ }^{*} \mathrm{p}<0.05$, using student $t$-test.

Fig. 3. Effects of indinavir on regulatory proteins in the insulin signalling pathway in CHO-IR cells. CHO-IR cells were treated with indinavir $(50 \mu \mathrm{M})$ for $16 \mathrm{~h}$ followed by insulin stimulation. The cells were then lysed and the lysates subjected to immunoblotting with antibodies against: (a) pS307 (b) PTP1B (c) SOCS-1 (d) SOCS-3 (e) SH2B (upper panels). The blots were then stripped and reprobed with anti-actin or anti-IRS (lower panels). Bound antibodies were visualised by chemiluminescence. Chemiluminescence was quantified by realtime imaging. The band intensity of the proteins from five independent experiments was normalized to the band intensity of actin or total IRS protein. Data are shown as the mean \pm S.E.M. $(\mathrm{n}=5)$. pS307 $=$ phosphorylated serine at residue 307 , tIRS-1 $=$ total IRS-1, PTP1B = protein tyrosine phosphatase $1 \mathrm{~B}$, SOCS-1 = suppressor of cytokines signalling 1, SOCS-3 = suppressor of cytokines signalling $3, \mathrm{SH} 2 \mathrm{~B}=\operatorname{Src}$ homology $2 \mathrm{~B},{ }^{*} \mathrm{p}<0.05$, using student $t$-test.

Fig. 4. Effects of indinavir on regulatory proteins in the insulin signalling pathway in 3T3-L1 adipocytes. 3T3-L1 adipocytes were treated with different concentrations of indinavir for $16 \mathrm{~h}$ before and after insulin stimulation. The cells were then lysed and the lysates subjected to immunoblotting with antibodies against: (a) pS307 (b) PTP1B (c) SOCS-1 (d) SOCS-3 (e) SH2B (f) APS (upper panels). The blots were then stripped and reprobed with anti-actin or anti-IRS-1 (lower panels). Bound antibodies were visualised by chemiluminescence. Chemiluminescence was quantified by realtime imaging. The band intensity of the proteins from six independent experiments was normalized to the band intensity of actin or total IRS-1 protein. Data are shown as the mean \pm S.E.M. $(n=6) \cdot p S 307=$ phosphorylated serine at residue 307, tIRS-1 = total IRS-1, PTP1B = protein tyrosine phosphatase $1 \mathrm{~B}$, SOCS-1 = suppressor of cytokines signalling 1 , SOCS-3 $=$ suppressor of cytokines signalling $3, \mathrm{SH} 2 \mathrm{~B}=$ Src homology $2 \mathrm{~B}, \mathrm{APS}=$ adapter protein with a pleckstrin homology domain and an SH2 domain, ${ }^{*} \mathrm{p}<0.05$, using student $t$-test.

Fig. 5. Abrogating effects of indinavir by sodium salicylate. CHO-IR cells were pre-treated with NaSal $\overline{(5 \mathrm{mM})}$ for $1 \mathrm{~h}$ prior to treatment with indinavir $(100 \mu \mathrm{M})$ for $16 \mathrm{~h}$. The cells were then stimulated with insulin for $5 \mathrm{~min}$ and then lysed and the lysates subjected to immunoblotting with antibodies against: (a) and (b) anti-phosphotyrosine PY20 antibody and (c) pS307 (upper panels). The blots were then stripped and reprobed with anti-IR, anti-IRS-1 and anti-actin (lower panels). Bound antibodies were visualised by chemiluminescence. Chemiluminescence was quantified by realtime imaging. The band intensity of the proteins from three independent experiments was normalized to the band intensity of total IR or IRS-1 protein. Data are shown as the mean \pm S.E.M. $(n=3)$. pIR PY20 = tyrosine phosphorylation of IR, $p$ IRS -1 PY20 = tyrosine phosphorylation of IRS- $1, \operatorname{tIR} \beta=$ total insulin receptor $\beta$-subunit, pS307 = phosphorylated serine at residue 307 of IRS-1, tIRS-1 = total IRS-1, ${ }^{*} \mathrm{p}<0.05$, using factorial-ANOVA. 
Figure 1

a)

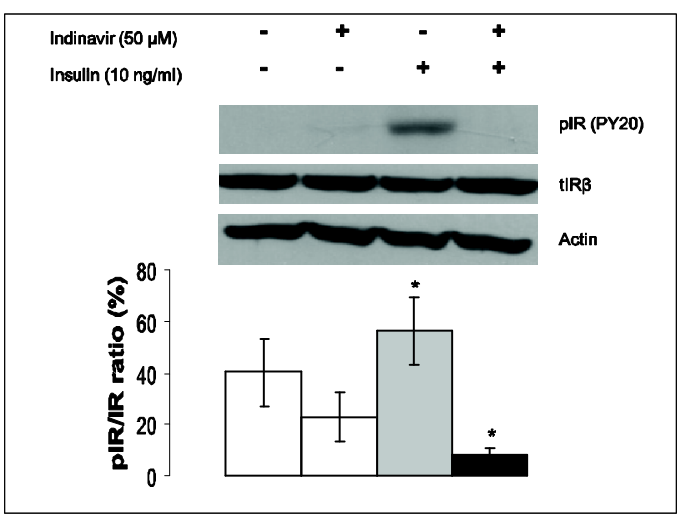

b)

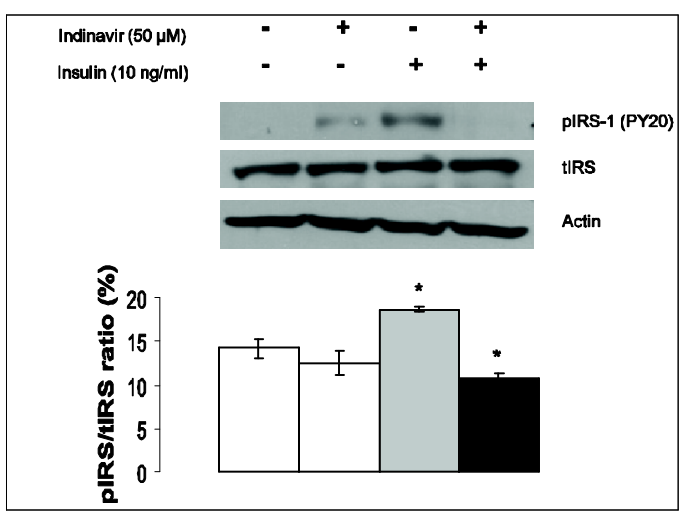


Figure 1c

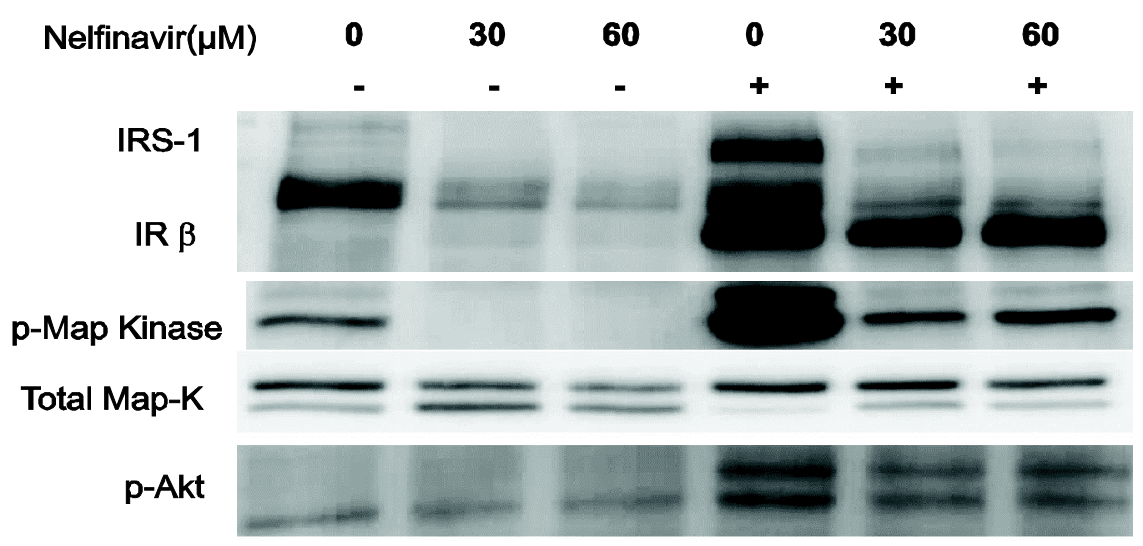

Total Akt
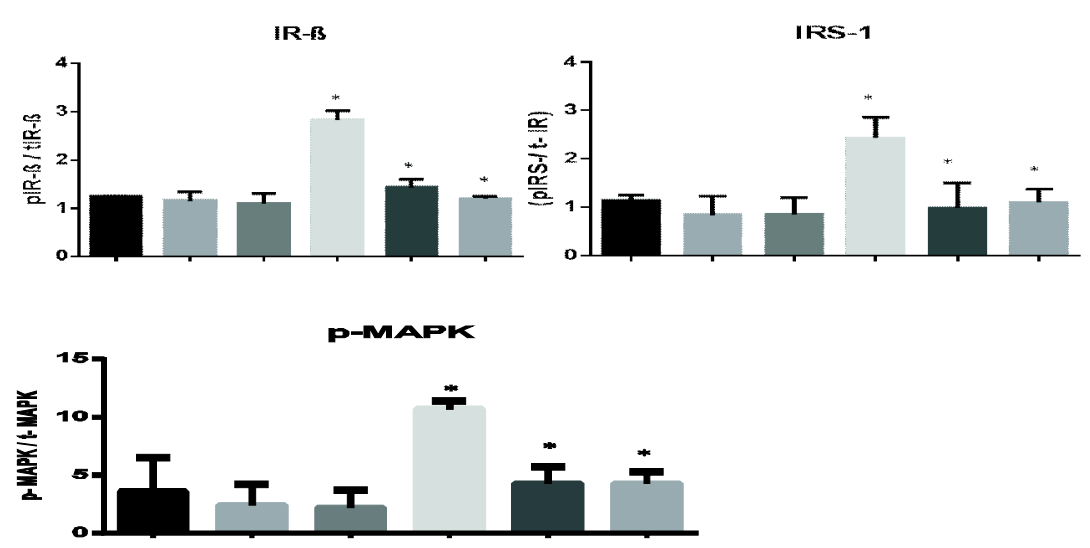
Figure 2

(a)
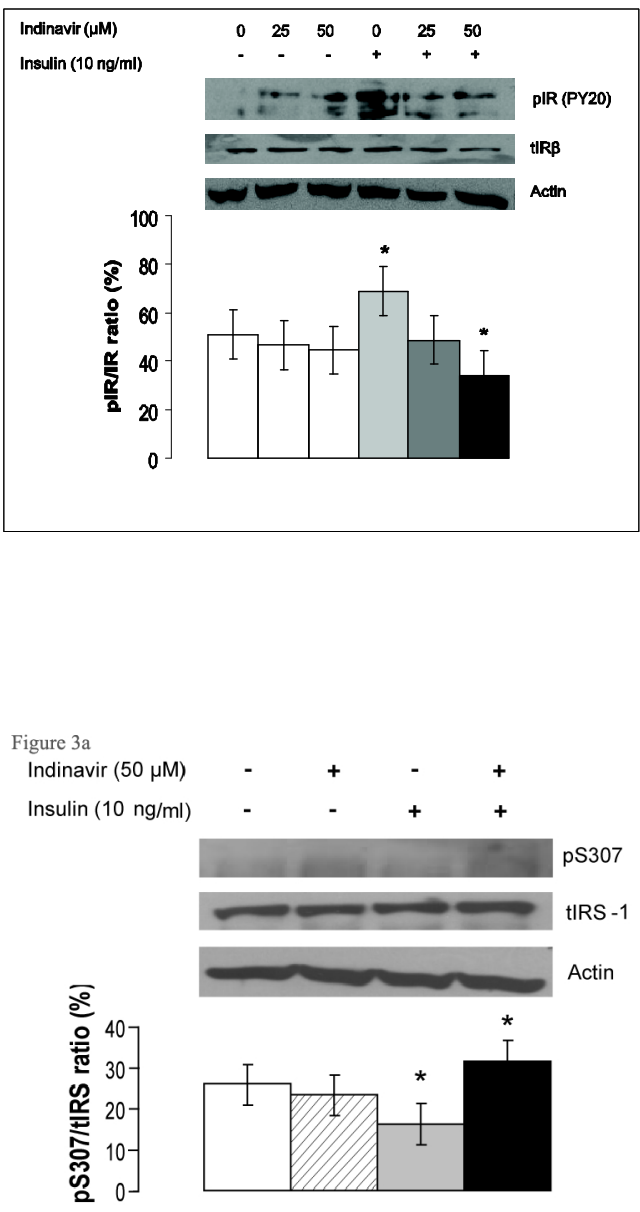

(b)

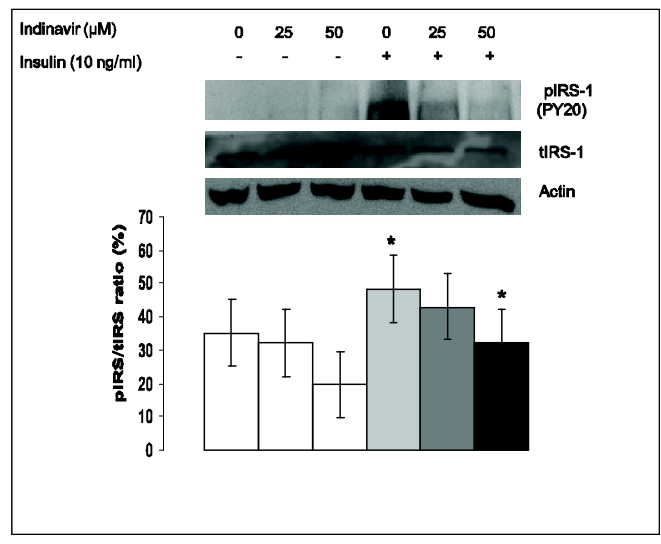

Figure 3b

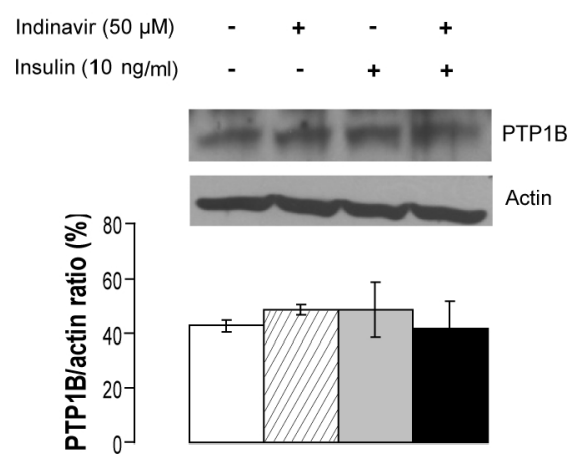




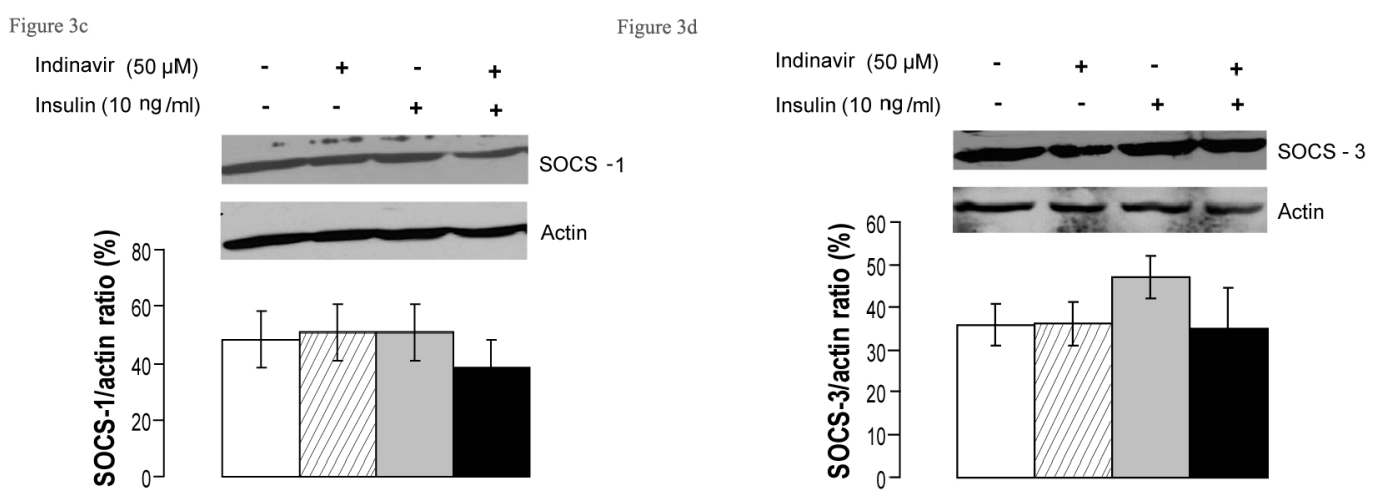

Figure 3e
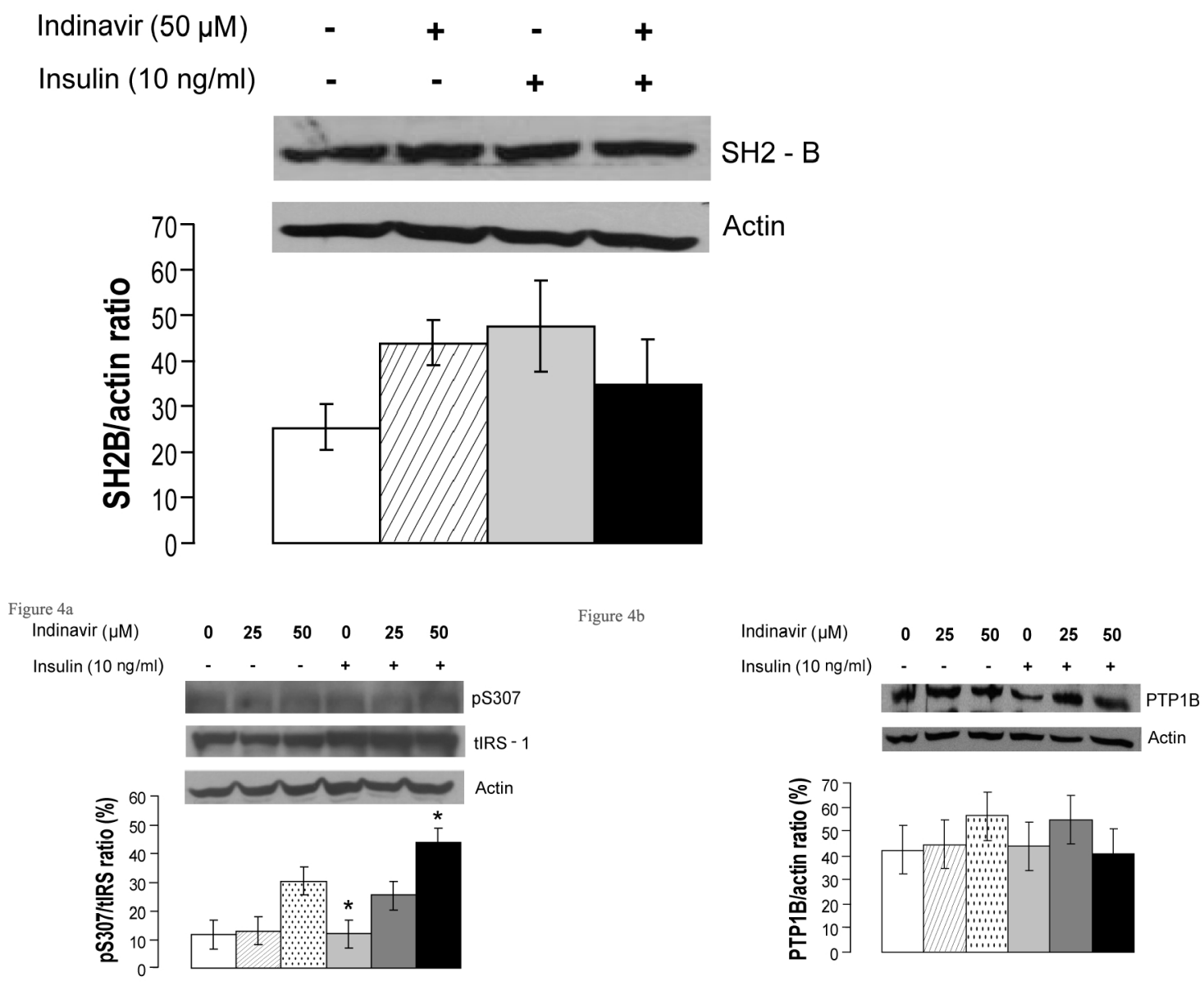
Figure $4 \mathrm{c}$
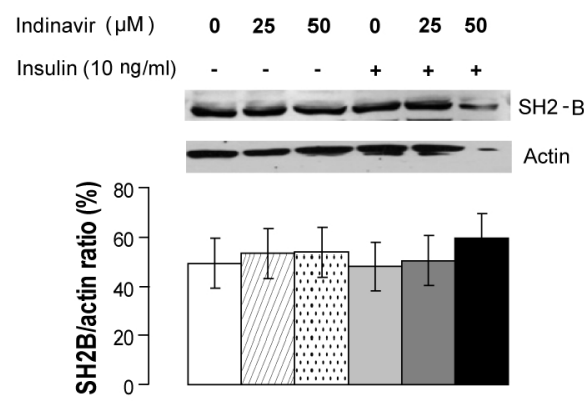

Figure 4d

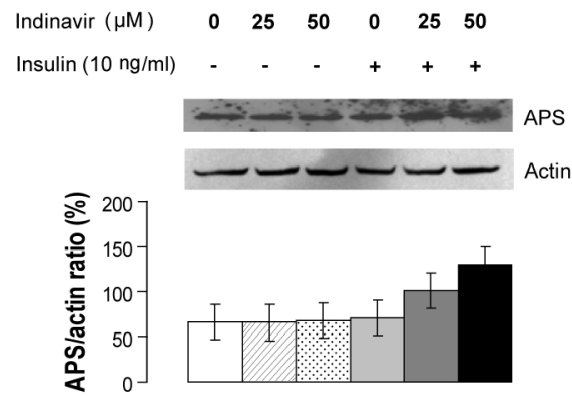

Figure 4e

$\begin{array}{lcccccc}\text { Indinavir }(\mu \mathrm{M}) & 0 & 25 & \mathbf{5 0} & \mathbf{0} & \mathbf{2 5} & \mathbf{5 0} \\ \text { Insulin }(10 \mathrm{ng} / \mathrm{ml}) & - & - & - & + & + & +\end{array}$

Figure 4f

$\sim=\operatorname{socs-1}$

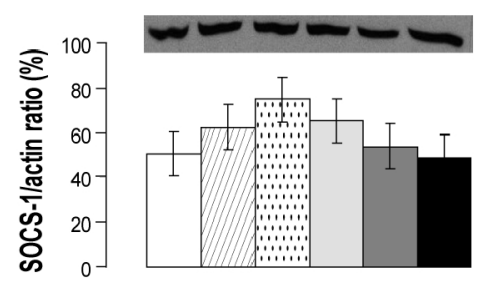

Figure 5a

Figure $5 b$
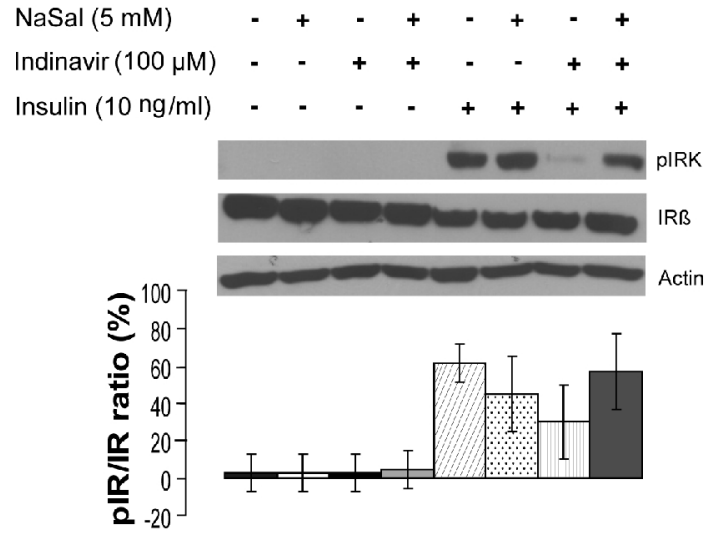

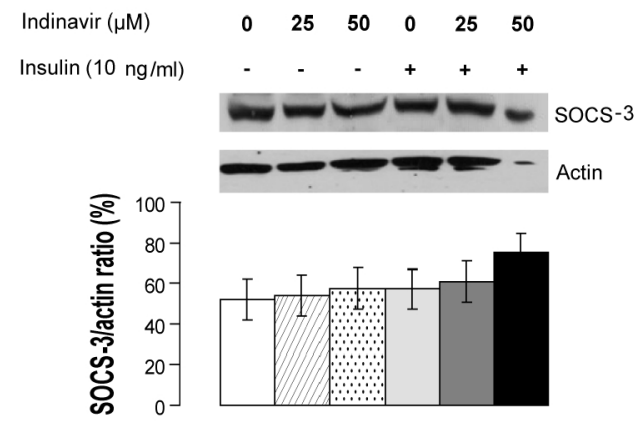

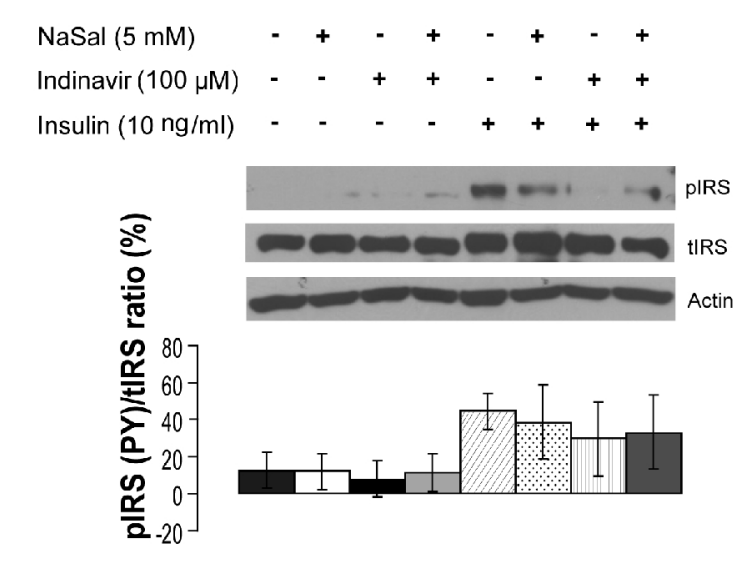


Figure 5c

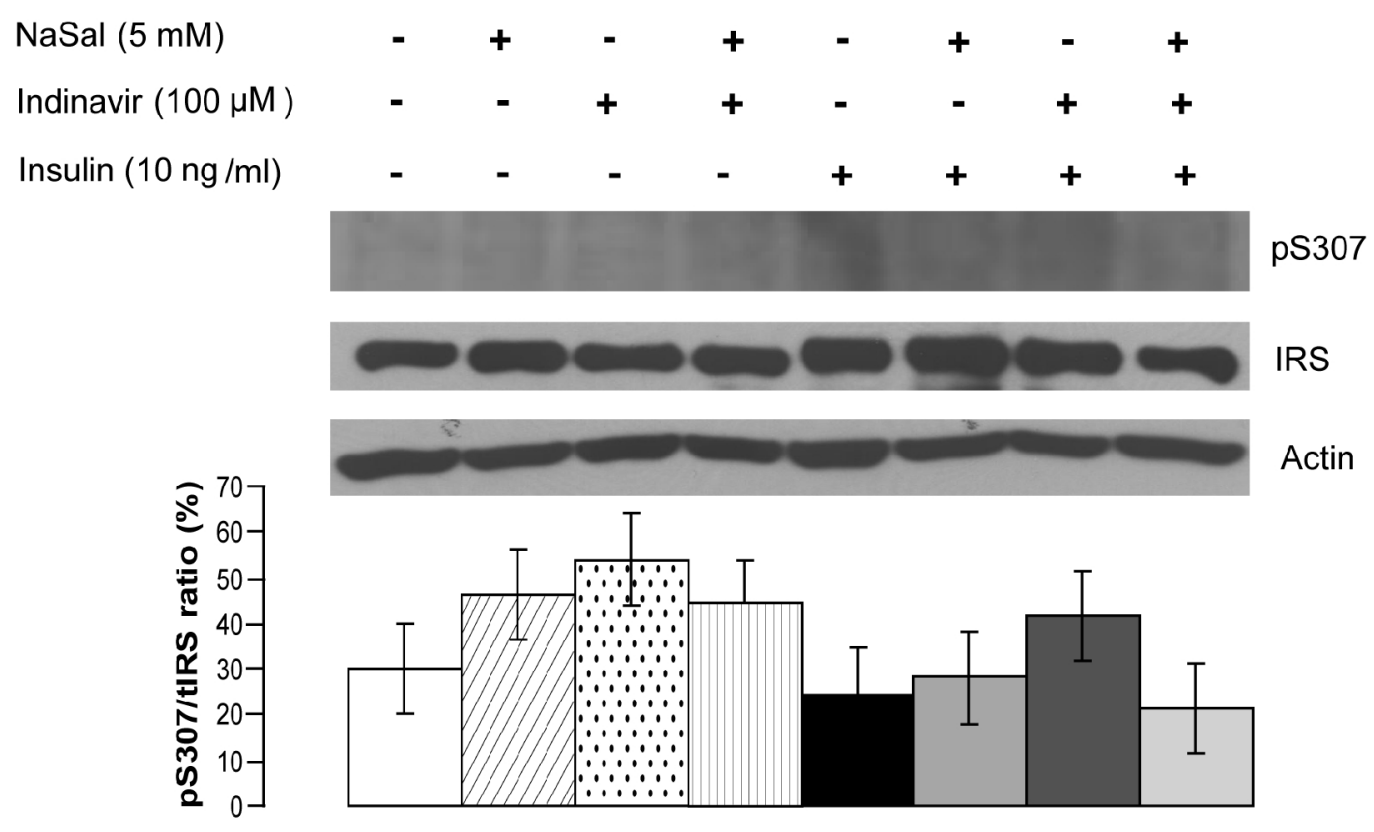

